\title{
Synthesis of Nanocrystalline $\mathrm{TiOF}_{2}$ Embedded in a Carbonaceous Matrix from $\mathrm{TiF}_{4}$ and D-Fructose
}

Claudio Evangelisti, Mohammad Hayatifar, Fabio Marchetti, Marcello Marelli, Guido Pampaloni, Fabio Piccinelli

\section{SUPPORTING INFORMATION}




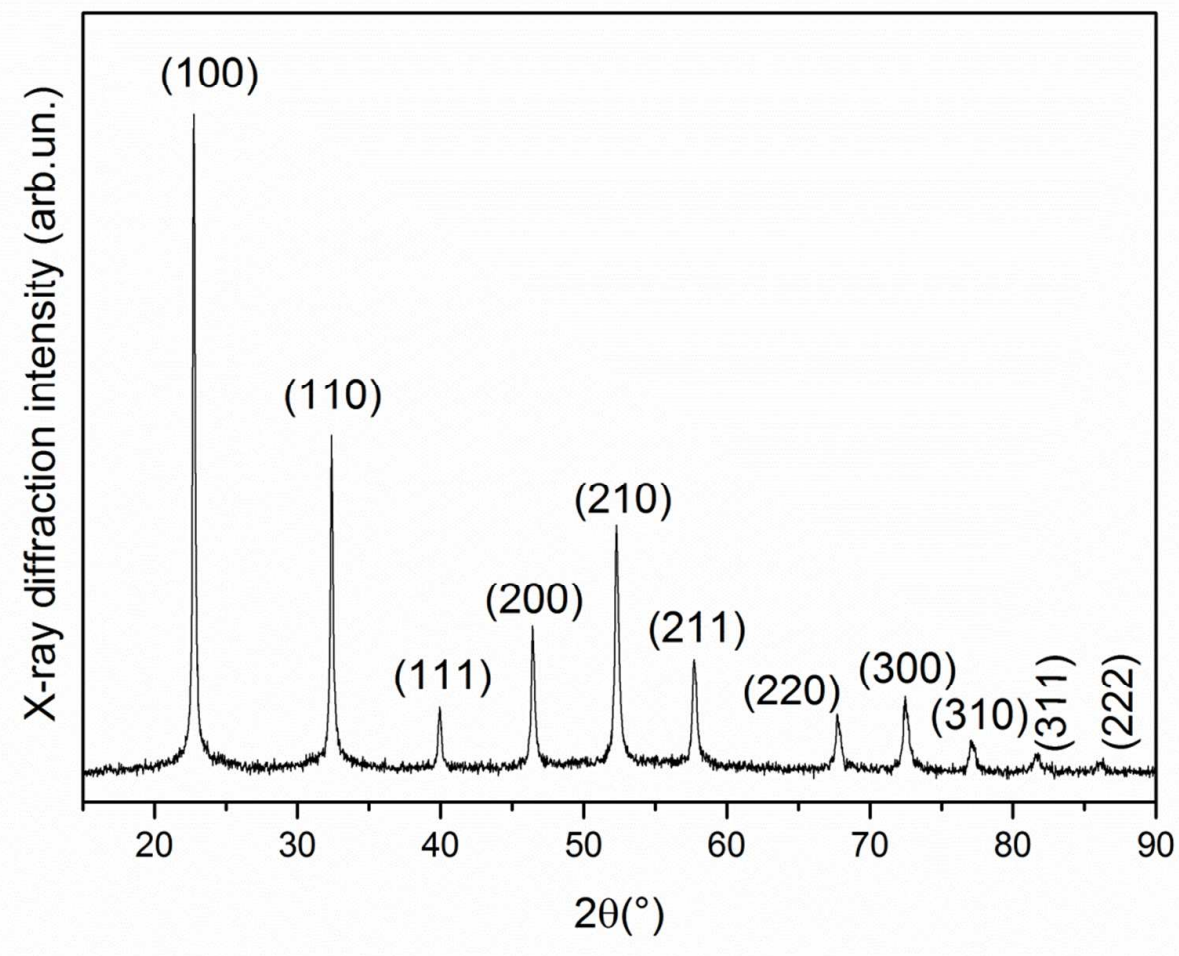

Figure S1. Indexed XRD powder pattern of cubic $\mathrm{TaO}_{2} \mathrm{~F}$. Average cristal size $=62(1) \mathrm{nm}$. Lattice parameter $\mathrm{a}=3.912(3)$ 